\title{
Tracheal Banding in Weanling Rats Diminishes Lung Growth and Alters Lung Architecture
}

\author{
KOZUI KIDA AND WILLIAM M. THURLBECK ${ }^{(2 K)}$ \\ Department of Pathologv. University of Manitoba, Faculty of Medicine, Winnipeg. Manitoba and Department of \\ Pathology, University of British Columbia, Vancouver, British Columbia, Canada
}

\begin{abstract}
Summary
We banded the trachea of 4-wk-old male rats and studied lung growth, lung morphometry, and static pulmonary mechanics 4 wk later. We compared the experimental animals to sham-operated male littermates of the same age, 8-wk-old normal male littermates, and weight-matched rats of a younger age. Tracheal banded animals were smaller and had significantly smaller absolute lung volumes, fewer alveoli, larger interalveolar wall distances, and increased alveolar duct size compared to the other groups. Their lung volumes were significantly smaller than were those of weightmatched controls. Air-filled pressure-volume curves from the tracheal ligation group were shifted to the left and upward when expressed as a percentage of total lung capacity or by fitting exponentials to the pressure-volume curves. There was no difference in saline-filled pressure-volume curves. We conclude that tracheal banding slows somatic growth and alters normal lung growth. Loss of elastic recoil appears to be due to alteration of surface forces.
\end{abstract}

In recent years, normal lung growth has been well documented in rats and mice $(2,5,12)$, but the situation is less clear in humans (23). Alveoli are absent in rats and mice at birth and the great majority of alveoli appear after birth in humans. It is possible that disease in the postnatal period may produce alterations in normal lung architecture or even predispose to lung injury in adult life. Clinical observations have suggested subsequent pulmonary abnormalities in patients with bronchial asthma (21) and after bronchiolitis (14), hydrocarbon pneumonitis (11), and bronchopulmonary dysplasia (3). Most studies are based on alterations of pulmonary function but some morphologic data are available (3). We have shown that normal lung growth did not occur in two patients after repair of congenital diaphragmatic hernia (24).

The present study was undertaken to investigate whether or not airway narrowing with consequent increased airway resistance influences lung growth. We anticipated that lung growth might be enhanced because tracheal ligation in fetal lambs increases lung weight (1). Instead, we found that tracheal banding of 4-wk-old rats results in altered and diminished lung growth.

\section{MATERIALS AND METHODS}

Nine 4-wk-old male Sprague-Dawley rats (Canadian Breeding Farms and Laboratory Limited, Quebec) were anesthetized with intraperitoneal sodium pentobarbital $(30 \mathrm{mg} / \mathrm{kg})$, and a midline incision was made in the neck. The trachea was exposed and mobilized, and a plastic template, $2 \mathrm{~cm}$ long and shaped to fit the front and sides of the trachea, was placed around the trachea 5 $\mathrm{mm}$ distal to the thyroid. Two silk ligatures, approximately $3 \mathrm{~mm}$ apart. were made firmly around the template which was then removed. These animals were then returned to their cages for 4 wk before sacrifice.

The same anesthesia and midline incision was performed in six control 4-wk-old male littermates with mobilization of the trachea but without placing ligatures. Eight 8-wk-old male normal rats, also littermates, were used for comparison as were a group of eight male rats matched for body weight from separate litters. These latter animals were approximately $7 \mathrm{wk}$ of age.

All the animals were kept in a room with controlled temperature and supplied with standard rat chow and water ad libitum. No antibiotics were administered. The animals were sacrificed under ether anesthesia by exsanguination via the abdominal aorta. The lungs were cannulated with Medicut cannulas (22G, Sheerwood, CO). Quasistatic, air-filled pressure-volume measurements were carried out (see below), and lung volume at $30 \mathrm{~cm} \mathrm{H}_{2} \mathrm{O}\left(\mathrm{V}_{30}\right)$ was thereby determined. The fresh weight of lung, diaphragm, and heart was measured. The right femur was removed, and the length from the top of the head to the medial condyle was measured. The lungs were inflated at a constant pressure $25 \mathrm{~cm}$ of formalin for at least $72 \mathrm{hr}$. Fixed lung volume $\left(\mathrm{V}_{\mathrm{L}}\right)$ was determined by water displacement at the end of the period of fixation. These lungs were used for subsequent morphometric study.

A block of tissue obtained from the left lung was sectioned longitudinally along the main bronchus. Paraffin-embedded tissue blocks were cut at $5 \mu \mathrm{m}$ thickness, and the first section beyond the bronchus was stained with hematoxylin and eosin and used for morphometric studies. The subsequent sections were stained with Humberston's elastic fibre (13) stain, but counter staining and nuclear staining were not done.

Transverse sections of the trachea were taken proximal and distal to the banded segment and from the banded segment and were placed on a slide glass with a small amount of glycerin to prevent dehydration. The internal area of the trachea was measured magnified on fresh samples. prepared as above, using a computer controlled digitizer. Narrowing was expressed as the ratio of the area of the banded segment to the mean area of the proximal and distal tracheal sections. Tracheal samples were taken from the other groups of animals corresponding to the proximal, intermediate, and distal samples in the experimental animals, and the internal areas were measured similarly.

\section{MORPHOMETRY}

The detailed techniques used for morphometry are described elsewhere (12). All of the morphometric data, except for the point counting data, were corrected by shrinkage factors, and this takes into account tissue shrinkage during processing, then referred to fresh lung tissue $\left(\mathrm{V}_{30}\right)$. No correction was made for thickness of histologic sections.

\section{AIR-FILLED PRESSURE-VOLUME CURVES}

The excised cannulated lungs were briefly rinsed in physiologic saline and degassed in a vacuum jar to a pressure of $200 \mathrm{~mm} \mathrm{Hg}$. The endotracheal tube was connected by a $\mathrm{Y}$-connector to a syringe which was attached to one limb and a Stratham p-23B B pressure transducer (Statham Lab., Hato Ray, Puerto Rico) connected to the other limb. Pressures were read from a galvanometer (Model 310; Triplett Co., Bluffon, $\mathrm{OH}$ ) calibrated by a water 
KIDA AND THURLBECK

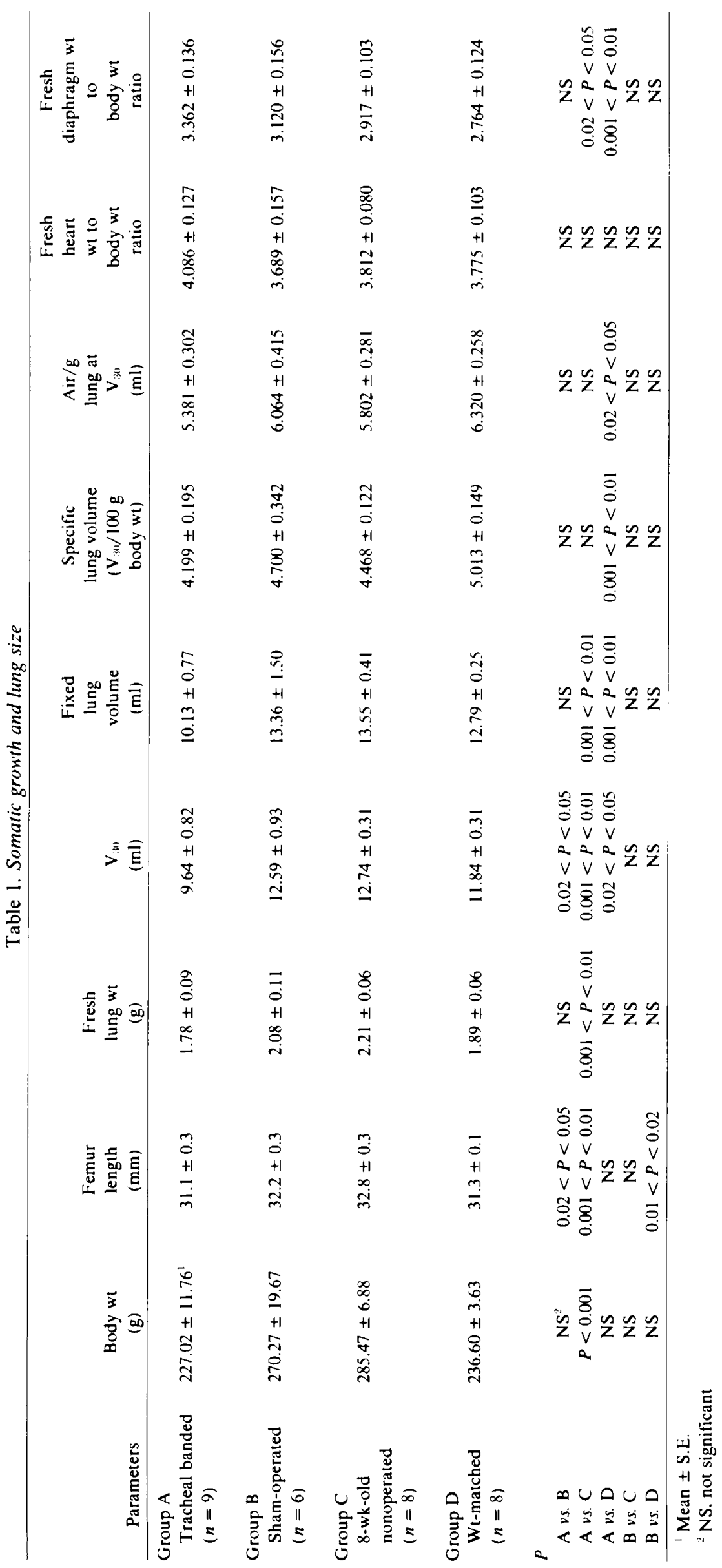


manometer. The lungs were inflated to a transpulmonary pressure of $30 \mathrm{~cm} \mathrm{H_{2 }}$ O with a stepwise air injection. The air volume at this point was designated as $\mathrm{V}_{30}$, then deflated similarly. The second deflation limb was recorded for pressure-volume measurements, and pressures were recorded when they became stable and volumes were expressed at ambient temperature and humidity. If the pressure did not remain constant, this was regarded as evidence of an air leak, and the lungs were discarded. Correction was made for Boyle's law effects. All the measurements were performed within $30 \mathrm{~min}$ after sacrifice. Each pressure-volume curve was determined by drawing the graphs, and the group data were calculated. The data were also analyzed by the best fit of a single exponential to the pressure-volume curve using a digital computer according to the methods of Colebatch et al. (6) and Gibson et al. (9), but differed in that all the data points greater than or equal to
$40 \%$ of $\mathrm{V}_{30}$ were included. Static compliance, expressed as air volume $(\mathrm{ml})$ per $\mathrm{cm} \mathrm{H}_{2} \mathrm{O}$ or as a percentage of maximum lung volume as determined by the exponential fit per $\mathrm{cm} \mathrm{H}_{2} \mathrm{O}$ was obtained from the slope of the regression line whose data points were between 40 and $70 \%$ of $V_{30}$.

\section{SALINE PRESSURE-VOLUME CURVES}

In a separate experiment, successive, static, saline-filled pressure-volume curves were performed on seven tracheal banded male rats, nine sham-operated controls, male littermates, and seven 8-wk-old male littermates according to the method of Mead et al. (18). Anesthetized rats were kept in a chamber with $100 \%$ oxygen for $5 \mathrm{~min}$. The chest was opened, and the lung was permitted to collapse while breathing continued. Then the trachea

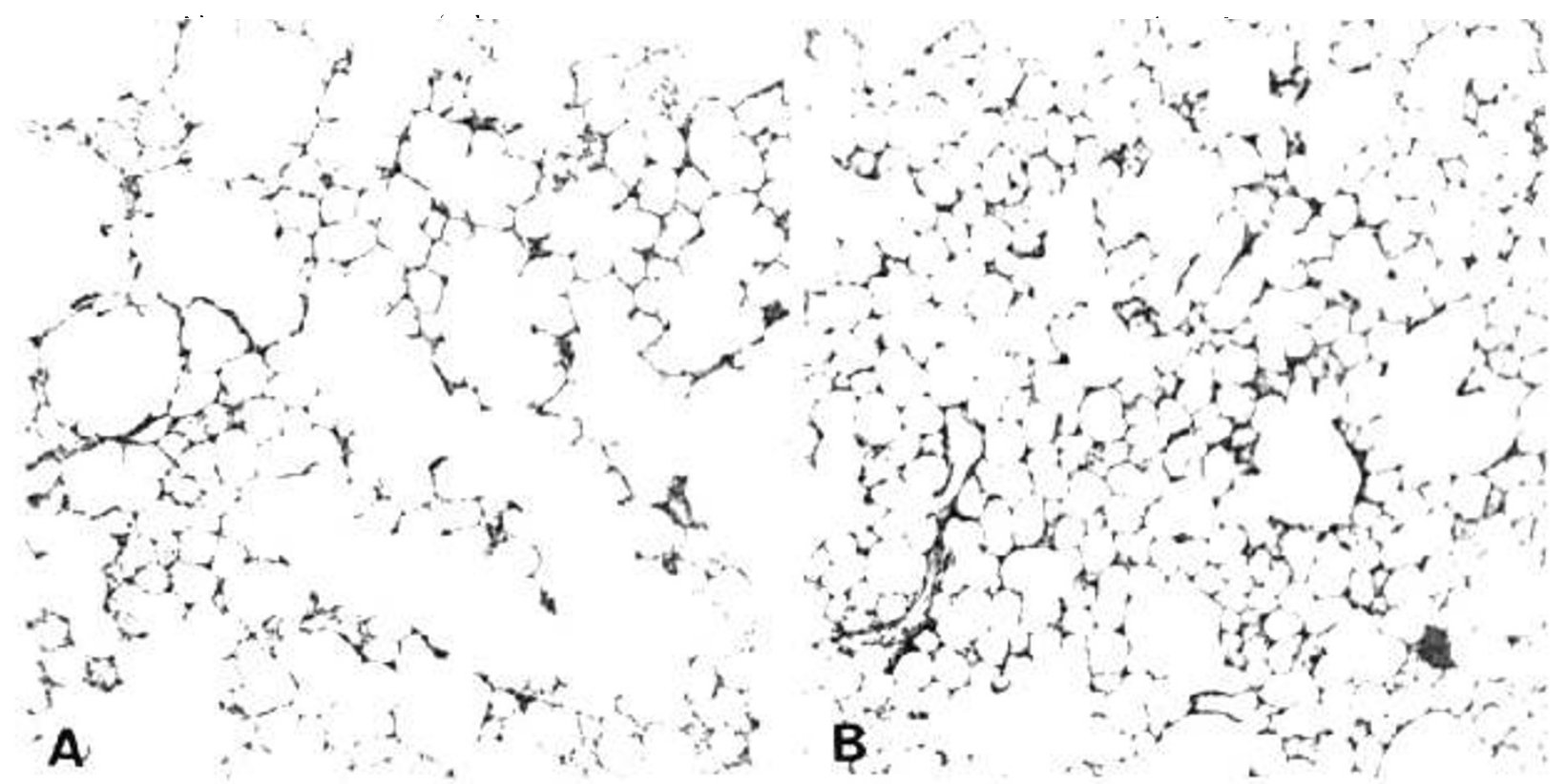

Fig. 1. $A$, tracheal banded rat lung. There is marked enlargement of alveolar ducts but no rupture of the alveolar walls; $B$, sham-operated rat lung for comparison. Both hematoxylin and eosin stain. Original magnification, $\times 100$.

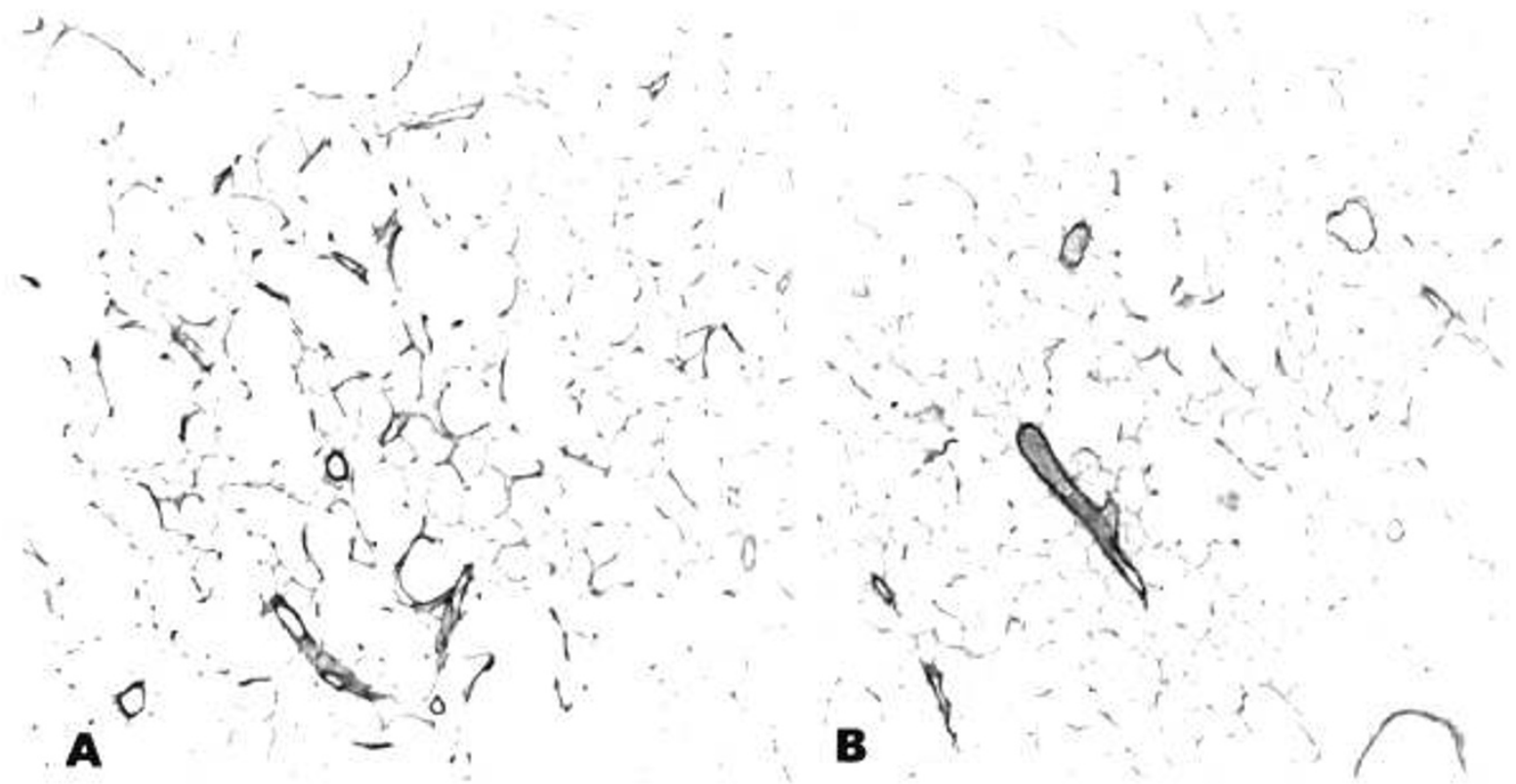

Fig. 2. $A$, tracheal banded rat lung. The elastic fibres appear increased in amount compared to the sham-operated rat lung $B$, both stained with Humberston's elastic fibre stain without counter- or nuclear staining. Original magnification, $\times 100$. 
KIDA AND THURLBECK

Table 2. Morphometric data

\begin{tabular}{|c|c|c|c|c|c|c|c|}
\hline \multirow[b]{2}{*}{ Group } & \multicolumn{7}{|c|}{ Volume proportion } \\
\hline & $\begin{array}{c}\text { Alveolar } \\
\text { air }\end{array}$ & $\begin{array}{l}\text { Duct } \\
\text { air }\end{array}$ & $\begin{array}{c}\text { Alveolar } \\
\text { wall }\end{array}$ & $\begin{array}{c}\text { Conduct. } \\
\text { air }\end{array}$ & $\begin{array}{l}\text { Blood } \\
\text { vessel }\end{array}$ & $\begin{array}{l}\text { Cond. } \\
\text { wall }\end{array}$ & $\begin{array}{c}\text { Connective } \\
\text { tissue }\end{array}$ \\
\hline \multicolumn{8}{|l|}{ A } \\
\hline $\begin{array}{l}\text { Tracheal banded } \\
(n=9)\end{array}$ & $0.414 \pm 0.22^{2}$ & $0.329 \pm 0.024$ & $0.172 \pm 0.007$ & $0.034 \pm 0.007$ & $0.024 \pm 0.009$ & $0.009 \pm 0.002$ & $0.018 \pm 0.007$ \\
\hline \multicolumn{8}{|l|}{ B } \\
\hline $\begin{array}{l}\text { Sham-operated } \\
(n=6)\end{array}$ & $0.458 \pm 0.022$ & $0.248 \pm 0.028$ & $0.193 \pm 0.021$ & $0.035 \pm 0.015$ & $0.029 \pm 0.009$ & $0.010 \pm 0.003$ & $0.021 \pm 0.007$ \\
\hline \multicolumn{8}{|l|}{$\mathrm{C}$} \\
\hline $\begin{array}{l}\text { 8-wk-old } \\
\text { normals } \\
(n=8)\end{array}$ & $0.489 \pm 0.018$ & $0.220 \pm 0.016$ & $0.190 \pm 0.013$ & $0.026 \pm 0.012$ & $0.050 \pm 0.010$ & $0.012 \pm 0.003$ & $0.013 \pm 0.003$ \\
\hline \multicolumn{8}{|l|}{ D } \\
\hline $\begin{array}{l}\text { wt-matched } \\
(n=8)\end{array}$ & $0.528 \pm 0.013$ & $0.199 \pm 0.017$ & $0.201 \pm 0.005$ & $0.023 \pm 0.009$ & $0.022 \pm 0.005$ & $0.009 \pm 0.005$ & $0.17 \pm 0.005$ \\
\hline \multicolumn{8}{|l|}{$P$} \\
\hline A vs. B & $\mathrm{NS}^{3}$ & $0.02<P<0.5$ & NS & NS & NS & NS & NS \\
\hline A vs. C & $0.02<P<0.05$ & $0.001<P<0.01$ & NS & NS & NS & NS & NS \\
\hline A v. D & $P<0.001$ & $P<0.001$ & $0.001<P<0.001$ & NS & NS & NS & NS \\
\hline B vs. C & NS & NS & NS & NS & NS & NS & NS \\
\hline B vs. D & $0.01<P<0.02$ & NS & NS & NS & NS & NS & NS \\
\hline C vs. D & NS & NS & NS & NS & $0.02<P<0.05$ & NS & NS \\
\hline
\end{tabular}

${ }^{1} V_{v}$ duct air, volume proportion of alveolar duct air; $N_{A}$, number of alveoli $/ \mathrm{cm}^{2}$; $N_{v}$ number of alveoli/ $\mathrm{cm}^{3} ;$ NAT, total number of alveoli; $S_{v}$, surface-to-volume ratio.

${ }^{2}$ Mean \pm S.E.

${ }^{3}$ NS, not significant.

was cannulated and clamped. Circulation continued for a period sufficient to render the lung gas free. The animals were killed by exsanguination via the abdominal aorta. The collapsed excised lung was suspended horizontally in a physiologic saline bath with a large surface area $\left(460 \mathrm{~cm}^{2}\right)$ and connected to a three-way stopcock through to a water manometer and a syringe filled with normal saline. The fluid levels in the bath and the water manometer were equilibrated, and a zero pressure baseline meniscus was established. Stepwise injections were made by filling the syringe until the transpulmonary pressure reached $20 \mathrm{~cm} \mathrm{H}_{2} \mathrm{O}$. The volume at $20 \mathrm{~cm} \mathrm{H}_{2} \mathrm{O}$ was designated as $\mathrm{V}_{20}$. Pressure readings were made immediately after the meniscus of the water manometer stabilized, and this often took 2 or $3 \mathrm{~min}$. Deflation pressurevolume relationships were measured in the same manner as 1.5 $\mathrm{ml}$ aliquots of saline were withdrawn. When the transpulmonary pressure reached zero, the lungs were removed from the saline bath and weighed. This weight minus the original weight gave the weight of the saline remaining in the lungs. The total number of grams of saline was equated to millilitres and was taken as a measure of lung volume. The first inflation and deflation limbs were recorded. The data were corrected for compliance of the apparatus and expressed as actual liquid volume $(\mathrm{ml})$, and as a percentage of $V_{2 k}$ plotted against the transpulmonary pressure $(\mathrm{cm}$ $\mathrm{H}_{2} \mathrm{O}$ ). Exponential best-fit equation was also determined similarly as in the air-filled pressure-volume curves using a digital computer.

\section{SCANNING ELECTRON MICROSCOPE}

For the scanning electron microscopic studies, a further five tracheal banded rats, five sham-operated controls, and four 8-wkold rats (all male littermates) were used. The animals were killed under sodium pentobarbital anesthesia by exsanguination via the abdominal aorta. Cannulated lungs were inflated using a $2.5 \%$ glutaraldehyde solution buffered with $0.05 \mathrm{M}$ sodium cacodylate ( $\mathrm{pH} \mathrm{7.4)} \mathrm{at} \mathrm{a} \mathrm{constant} \mathrm{pressure} \mathrm{of} 25 \mathrm{~cm} \mathrm{H} \mathrm{H}_{2} \mathrm{O}$ for one hr at $4^{\circ} \mathrm{C}$. Then the sample was cut into small pieces and postfixed in buffered osmium tetroxide. The specimens were dehydrated by series of ethanol and placed into a freeze dryer (Unitrap II: Vertis Co., Gardiner, NY) overnight and coated with gold. Observations were made by a scanning electron microscope (Super-SEM ISI: International Scientific Instruments, San Jose, CA) (25 kV).

\section{QUANTITATIVE ANALYSIS OF ELASTIC FIBRES IN LUNG TISSUE}

Twenty-two random fields from each slide stained with Humberston's stain were assessed using a commercially available image analyzer. Using maximum contrast, the number of picture points (pixels) appearing dark was recorded, and the result was expressed as the average number of pixels per field per animal.

\section{STATISTICS}

The two-tailed Student $t$ test was used for statistical comparison with the significance level at $P<0.05$. Results are presented as group means $\pm 1 \mathrm{~S}$.E.

\section{RESULTS}

The cross-sectional area of the banded trachea was $26.2 \pm 1.8 \%$ (mean \pm S.E.) of the average cross-sectional area proximal and distal to it. Tracheal banding resulted in mild inspiratory stridor and intercostal retraction during normal breathing. The data concerning somatic growth and lung size are presented in Table 1. Body weight at the start of the experiment was $76.94 \pm 1.17$ (mean \pm S.E.) g, and there was no significant difference between the groups. At the end of the experiment, the tracheal banded animals weighed less, had shorter femurs and smaller lungs, and had relatively larger diaphragms than did the 8-wk-old shamoperated controls and the nonoperated rats. The differences were more often significant when compared to normals than when compared to controls. Distended lung volumes, specific lung volumes $\left(V_{: 3}\right.$ per $100 \mathrm{~g}$ body weight $)$, and the amount of air per gram of lung tissue were significantly smaller in the experimental animals compared to the weight-matched rats, and the relative and absolute diaphragm weights were significantly larger. The heart weight/body weight ratio tended to be larger in the banded animals but did not reach significant levels.

Gross examination of the lungs revealed no abnormalities in any of the groups. The most striking feature in the histologic 


\begin{tabular}{|c|c|c|c|c|c|c|}
\hline $\begin{array}{c}\text { Mean } \\
\text { interalveolar } \\
\text { wall distance: } \\
\mathbf{L}_{\mathrm{m}}(\mu) \\
\end{array}$ & $\begin{array}{c}V_{\mathrm{v}} \text { duct } \\
\text { air } \times \mathrm{L}_{\mathrm{m}}(\mu) \\
\end{array}$ & $\mathrm{N}_{\mathrm{A}} \times 10^{4}$ & $\mathrm{~N}_{\mathrm{v}} \times 10^{5}$ & NAT $\times 10^{i}$ & $\begin{array}{c}\text { Alveolar surface } \\
\text { area }\left(\mathrm{m}^{2}\right)\end{array}$ & $\begin{array}{l}S_{1} \times 10 \\
\left(\mathrm{~cm}^{1}\right)\end{array}$ \\
\hline $115.31 \pm 6.53$ & $38.59 \pm 4.70$ & $19.876 \pm 0.839$ & $28.309 \pm 1.572$ & $29.430 \pm 2.530$ & $0.3744 \pm 0.0359$ & $38.414 \pm 1.613$ \\
\hline $94.94 \pm 4.43$ & $23.82 \pm 3.25$ & $26.136 \pm 2.991$ & $42.165 \pm 8.316$ & $51.142 \pm 5.749$ & $0.5668 \pm 0.0735$ & $42.583 \pm 1.938$ \\
\hline $94.75 \pm 4.93$ & $21.27 \pm 2.32$ & $26.954 \pm 1.324$ & $41.039 \pm 2.668$ & $61.755 \pm 5.649$ & $0.6395 \pm 0.0456$ & $42.642 \pm 2.108$ \\
\hline $94.03 \pm 2.35$ & $18.90 \pm 1.86$ & $23.123 \pm 0.822$ & $31.233 \pm 1.362$ & $43.052 \pm 2.236$ & $0.5799 \pm 0.0136$ & $44.182 \pm 1.165$ \\
\hline $0.02<P<0.05$ & $0.02<P<0.05$ & $0.02<P<0.05$ & NS & $0.001<P<0.01$ & $0.02<P<0.05$ & $0.01<P<0.02$ \\
\hline $0.02<P<0.05$ & $0.001<P<0.01$ & $P<0.001$ & $P<0.001$ & $P<0.001$ & $P<0.001$ & $0.01<P<0.02$ \\
\hline $0.01<P<0.02$ & $0.001<P<0.01$ & $0.01<P<0.02$ & NS & $0.001<P<0.01$ & $P<0.001$ & $P<0.001$ \\
\hline NS & NS & NS & NS & NS & NS & NS \\
\hline NS & NS & NS & NS & NS & NS & NS \\
\hline NS & NS & $0.02<P<0.05$ & $0.001<P<0.01$ & $0.001<P<0.01$ & NS & NS \\
\hline
\end{tabular}

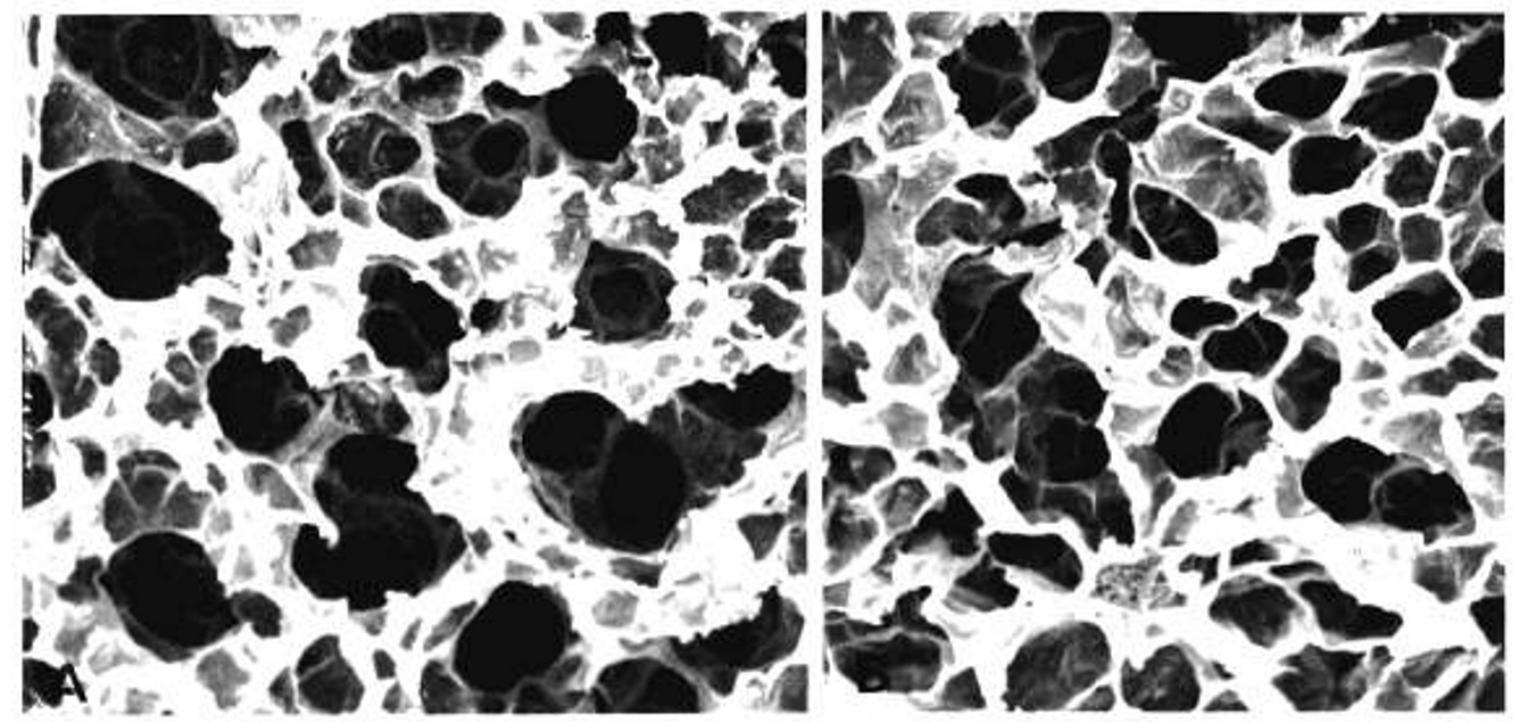

Fig. 3. A, scanning electron micrographs of tracheal banded rat lung. The alveolar ducts are enlarged, but increase in size or number of Kohn's pores cannot be seen; $B$, sham-operated rat lung for comparison. Both are original magnification $\times 160$.

sections of the tracheal banded animals was that the alveolar ducts (the core of the air internal to alveoli in alveolar ducts and sacs) were enlarged (Fig. 1). This was uniformly present throughout the lung. No destruction of alveolar parenchyma was found. Microscopic assessment of the elastic fibre of the lungs from four groups was carried out using the Humberston's elastic fibre stain and suggested an increase in stainable tissue in the ligated group (Fig. 2). Scanning micrographs of the tracheal ligated lung showed that there was a ductectasia in the tracheal ligated group (Fig. 3).

Morphometric data are shown in Table 2. The tracheal banded animals had a smaller volume proportion of alveolar air and a larger volume proportion of alveolar duct air than the other groups, and the differences were significant except for the alveolar air difference between the tracheal banded animals and the shamoperated controls. The volume proportion of alveolar wall was less in the tracheal banded animals than in the weight-matched group. The average interalveolar wall distance and the average duct air distance were significantly increased in the tracheal banded animals. The number of alveoli per unit area, the total number of alveoli, alveolar surface area, and the surface-to-volume ratio was significantly decreased in the tracheal banded animals compared to the other groups. The number of alveoli per unit volume was smaller in the banded animals than in controls and unoperated animals, and this difference was significant when compared to the unoperated animals. This difference implies that average alveolar volume was increased in the banded animals.

The quasistatic, air-filled pressure-volume deflation curves are shown in Figure 4. Major differences are apparent when the pressure-volume curves are expressed in absolute volumes derived from an exponential fit (Fig. $4 A$ ) primarily reflecting changes in lung volumes. When expressed as percentage of $V_{: 31}$. then most of the differences disappear (Fig. $4 B$ ), but the tracheal-banded group 
have a significantly lower transpulmonary pressure above $50 \%$ of $\mathrm{V}_{30}$, suggesting loss of elastic recoil at medium and high lung volumes. The shape constant $(\mathrm{K})$ was significantly higher in the tracheal-banded animal than in the sham-operated and agematched groups (Table 3). Compliance was significantly decreased in the banded rats compared to sham-operated controls and 8-wkold animals, but this difference disappeared when this was expressed as a percentage of $\mathbf{V}_{30}$. Saline-filled pressure-volume deflation curves (Fig. 5) were similar in the groups when normalized for lung volume, suggesting that the differences noted in the airfilled pressure-volume curve were not due to tissue forces. The calculated values shown in Table 4 support these observations and show that there was no difference in compliance between the groups. It is also apparent that the exponential equation fits the saline-filled pressure-volume curves less well than air-filled pressure-volume curves.

Table 5 shows the number of pixels stained by Humberston's elastic stain. The tracheal-banded animal had a higher volume

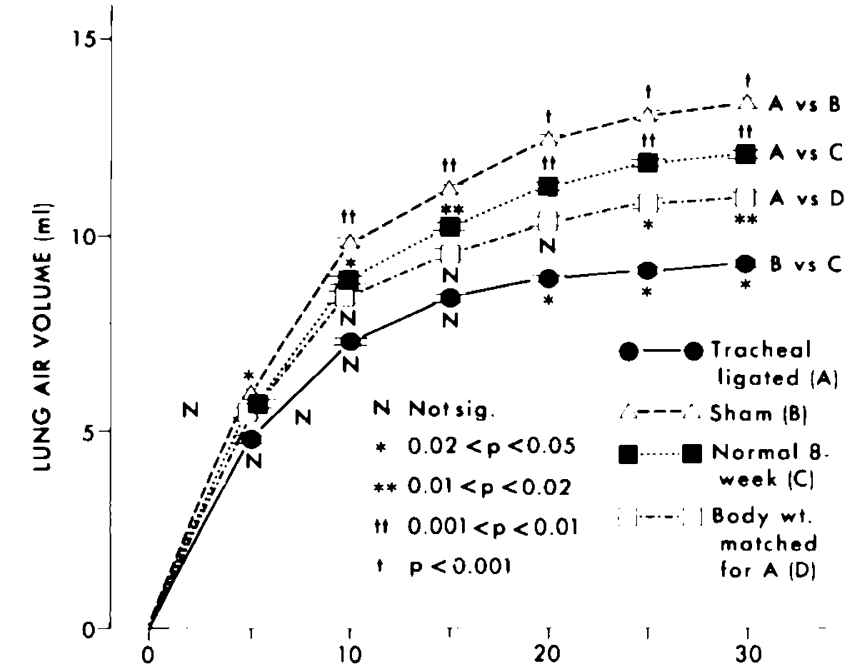

A

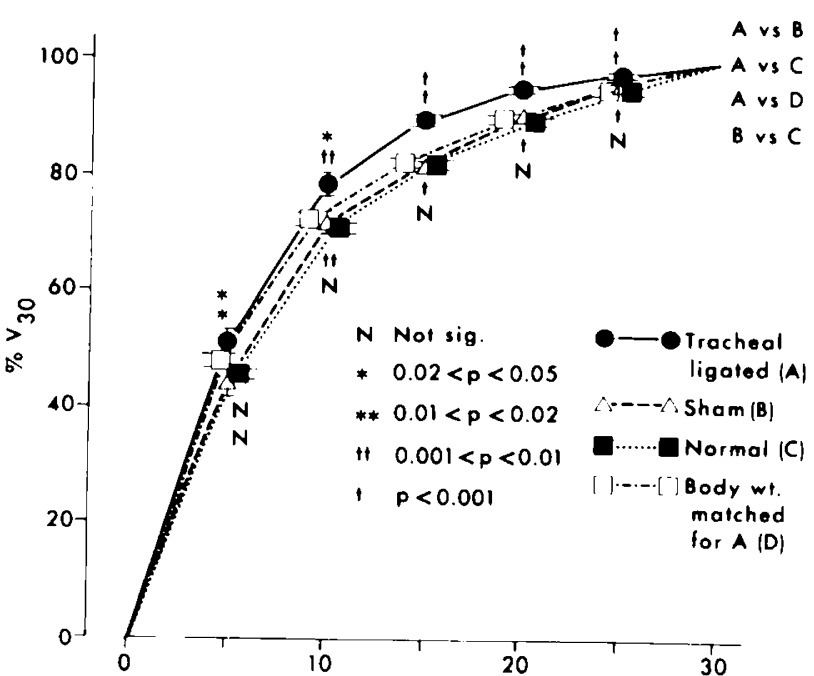

TRANSPUIMONARY PRESSURE $\left(\mathrm{cm} \mathrm{H} \mathrm{H}_{2} \mathrm{O}\right.$ )

Fig. 4. Quasistatic, air-filled pressure-volume curves. Lung volume $(\mathrm{ml})$ is plotted against transpulmonary pressure $\left(\mathrm{cm} \mathrm{H}_{2} \mathrm{O}\right)(A)$. Percentage of $\mathrm{V}_{3 \%}$ is plotted against transpulmonary pressure $\left(\mathrm{cm} \mathrm{H}_{2} \mathrm{O}\right)(B)$. There are no significant differences between groups $B$ and $C$. $Q$, tracheal ligated $(A) ; \triangle$, shamoperated (B); normal 8-wk-old (C); $\square$, body weight matched for tracheal ligation (D).

Table 3. Calculation values of air-filled pressure-volume measurements

\begin{tabular}{|c|c|c|c|c|c|c|}
\hline \multirow[b]{2}{*}{ Variables } & \multirow[b]{2}{*}{$K$} & \multirow[b]{2}{*}{$V_{\max }{ }^{1}$} & \multirow[b]{2}{*}{$b$} & \multicolumn{2}{|c|}{ Compliance } & \multirow[b]{2}{*}{$\begin{array}{c}\text { Exponential } \\
\text { equation } \\
\text { and } R^{2}\end{array}$} \\
\hline & & & & $\frac{\text { Volume }(\mathrm{ml})}{P\left(\mathrm{~cm} \mathrm{H}_{2} \mathrm{O}\right)}$ & $\frac{\text { Volume }\left(\%, V_{30}\right)}{P\left(\mathrm{~cm} \mathrm{H}_{2} \mathrm{O}\right)}$ & \\
\hline \multicolumn{7}{|l|}{ Group A } \\
\hline $\begin{array}{l}\text { Tracheal banded } \\
(n=9)\end{array}$ & $0.151 \pm 0.008^{2}$ & $9.356 \pm 0.697$ & $9.904 \pm 0.795$ & $0.653 \pm 0.050$ & $6.917 \pm 0.441$ & $\begin{array}{c}V=9.356-9.904 e^{-0.151} \\
0.9947\end{array}$ \\
\hline \multicolumn{7}{|l|}{ Group B } \\
\hline $\begin{array}{l}\text { Sham-operated } \\
(n=6)\end{array}$ & $0.113 \pm 0.010$ & $14.010 \pm 0.382$ & $11.897 \pm 0.778$ & $0.922 \pm 0.083$ & $6.660 \pm 0.734$ & $\begin{array}{c}V=14.010-11.897 e^{0.11: 3} \\
0.9912\end{array}$ \\
\hline \multicolumn{7}{|l|}{ Group C } \\
\hline $\begin{array}{l}\text { Nonoperated } \\
8 \text {-wk-old } \\
(n=8)\end{array}$ & $0.096 \pm 0.005$ & $12.930 \pm 0.326$ & $10.021 \pm 0.376$ & $0.824 \pm 0.054$ & $6.346 \pm 0.316$ & $\begin{array}{c}V=12.930-10.021 e^{-01 .(x) * 6} \\
0.9927\end{array}$ \\
\hline \multicolumn{7}{|l|}{ Group D } \\
\hline $\begin{array}{l}\text { Wt-matched } \\
(n=8)\end{array}$ & $0.130 \pm 0.009$ & $11.444 \pm 0.282$ & $10.564 \pm 0.550$ & $0.800 \pm 0.051$ & $7.176 \pm 0.550$ & $\begin{array}{c}V=11.44-10.564 e^{-0.133)} \\
0.9887\end{array}$ \\
\hline \multicolumn{7}{|l|}{$P$} \\
\hline $\mathrm{A}$ vs. B & $0.001<P<0.01$ & $P<0.001$ & NS & $0.01<P<0.02$ & NS & \\
\hline A vs. C & $P<0.001$ & $P<0.001$ & NS & $0.02<P<0.05$ & NS & \\
\hline A vs. D & NS & $0.01<P<0.02$ & NS & NS & NS & \\
\hline B vs. C & NS & NS & $0.02<P<0.05$ & NS & NS & \\
\hline B vs. D & NS & $P<0.001$ & NS & NS & NS & \\
\hline
\end{tabular}

${ }^{1}$ The equation $V=V_{\max }-b e^{-\kappa_{p} p}$ fits a single exponential to the pressure-volume curve where $V$ is volume at pressure $p$, and $V_{\max }$ is the lung volume at $\infty$ pressure. $b$ is a constant. $R^{2}$, proportion of total variance accounted for by the regression equation. NS, not significant.

${ }^{2}$ Mean \pm S.E. 


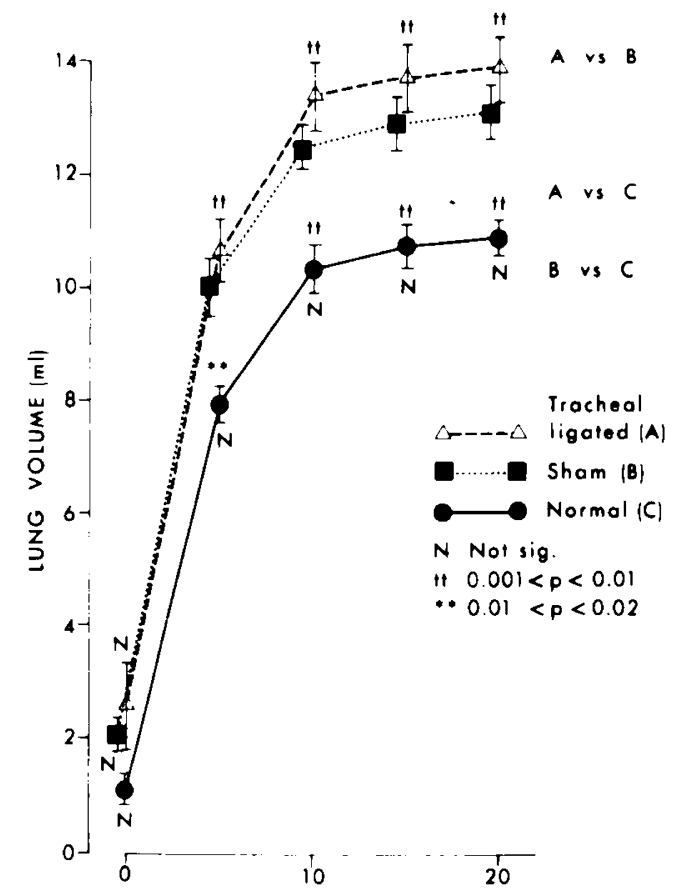

A TRANSPULMONARY PRESSURE $\mathrm{l} \mathrm{cm} \mathrm{H} \mathrm{H}_{2} \mathrm{O}$

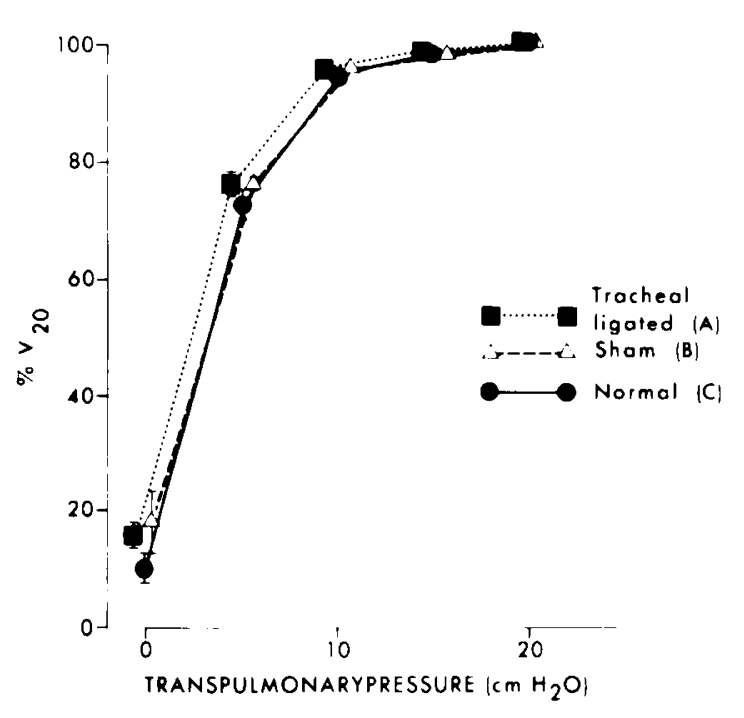

B

Fig. 5. Saline-filled pressure-volume curves. Lung volume $(\mathrm{ml})$ is plotted against transpulmonary pressure $\mathrm{cm}^{\mathrm{H}_{2}} \mathrm{O}(A)$. Percentage of $\mathrm{V}_{2 n}$ is plotted against transpulmonary pressure $\left(\mathrm{cm} \mathrm{H}_{2} \mathrm{O}\right)(B)$. There are no significant changes between the three groups in $B$. $\bullet$, tracheal ligated $(A) ; \triangle$, shamoperated (B): normal 8-wk-old (C).

Table 4. Calculation values of saline-filled pressure-volume measurements

\begin{tabular}{|c|c|c|c|c|c|c|}
\hline \multirow[b]{2}{*}{ Variables } & \multirow[b]{2}{*}{$V_{\text {mux }}{ }^{1}$} & \multirow[b]{2}{*}{$b$} & \multirow[b]{2}{*}{$K$} & \multicolumn{2}{|c|}{ Compliance } & \multirow{2}{*}{$\begin{array}{c}\text { Exponential } \\
\text { equation } \\
\text { given } \\
\text { and } R^{2}\end{array}$} \\
\hline & & & & $(\mathrm{ml}) / \mathrm{cm} \mathrm{H}{ }_{2} \mathrm{O}$ & $\% V_{201} / \mathrm{cm} \mathrm{H}{ }_{2} \mathrm{O}$ & \\
\hline \multicolumn{7}{|l|}{ Group A } \\
\hline $\begin{array}{l}\text { Tracheal banded } \\
(n=5)\end{array}$ & $11.69 \pm 0.66^{2}$ & $9.39 \pm 0.66$ & $0.1780 \pm 0.0144$ & $1.344 \pm 0.109$ & $15.294 \pm 1.640$ & $\begin{array}{c}V=11.69-e^{-10.1780 p} \\
0.9544\end{array}$ \\
\hline \multicolumn{7}{|l|}{ Group B } \\
\hline $\begin{array}{l}\text { Sham-operated } \\
(n=6)\end{array}$ & $15.50 \pm 0.92$ & $12.43 \pm 0.88$ & $0.1738 \pm 0.0111$ & $1.572 \pm 0.230$ & $11.555 \pm 1.001$ & $\begin{array}{c}V=15.50-e^{-0.17301 p} \\
0.9674\end{array}$ \\
\hline \multicolumn{7}{|l|}{ Group C } \\
\hline $\begin{array}{l}8 \text {-wk-old } \\
\text { normals } \\
(n=5)\end{array}$ & $15.43 \pm 0.91$ & $12.72 \pm 1.14$ & $0.1631 \pm 0.0121$ & $1.706 \pm 0.202$ & $11.252 \pm 1.687$ & $\begin{array}{c}V=15.43-e^{-0.16 i 31 p} \\
0.9637\end{array}$ \\
\hline \multicolumn{7}{|l|}{$P$} \\
\hline A vs. B & $0.01<P<0.02$ & $0.02<P<0.05$ & NS & NS & NS & \\
\hline A vs. C & $0.01<P<0.02$ & $0.02<P<0.05$ & NS & NS & NS & \\
\hline B vs. C & NS & NS & NS & NS & NS & \\
\hline
\end{tabular}

'Definitions and abbreviations: see Table 3.

2 Mean \pm S.E.

proportion of elastic tissue than the other groups. This was significant when compared to the 8-wk-old control animals and had a significance of $P=0.05$ for the other two contrasting groups.

\section{DISCUSSION}

Tracheal banding resulted in diminished somatic growth so that the experimental animals weighed less than 8-wk-old normal rats and had shorter femurs than 8-wk-old rats and sham-operated animals. Others have similarly showed growth retardation of tracheal-banded animals (15). We have attributed the alteration in somatic growth to the banding procedure. An external reviewer of this article suggested that this may have been due to interference with thyroid function due to the surgery. We have no anatomical or functional data to consider this hypothesis.

Differences in body size make interpretation of lung volume changes difficult, but air-filled lung volumes at a transpulmonary pressure of $30 \mathrm{~cm} \mathrm{H}_{2} \mathrm{O}$ were smaller than weight-matched rats as well as the other two groups.

Tracheal banding had a striking effect on lung architecture with 
Table 5. Quantitative analysis of elastic fibres

\begin{tabular}{lcccc} 
& & Group A & Group D \\
No. of picture points & $\begin{array}{c}\text { Group B } \\
\text { Tracheal banded } \\
\text { of elastic fibre }\end{array}$ & $\begin{array}{c}\text { Sham-operated } \\
(n=8)\end{array}$ & $\begin{array}{c}\text { Non-operated } \\
8 \text {-week-old } \\
(n=14)\end{array}$ & $\begin{array}{c}\text { Size-matched } \\
\text { non-operated } \\
(n=6)\end{array}$ \\
\hline Mean \pm I S.E. & $8446 \pm 860^{1}$ & $6800 \pm 502$ & $5936 \pm 509$ & $6184 \pm 373$
\end{tabular}

Comparison among four groups

\begin{tabular}{lc} 
A vs. B & $P=0.05$ \\
A v.s. C & $0.01<P<2.02$ \\
A v.s. D & $P=0.05$ \\
B v.s. C & NS \\
B vis. D & NS \\
\hline
\end{tabular}

${ }^{\prime}$ Mean \pm S.E.

greatly increased alveolar duct volume, defined as the core of air central to alveoli in alveolar ducts and sacs. This was accompanied by increased interalveolar wall distance, a diminished surface to volume ratio, and diminished alveolar surface area. In addition, there was marked alteration in alveolar multiplication so that the banded animals had less than one-half the number of alveoli of normal 8-wk-old rats and about $\% / 3$ the number of alveoli of younger, size-matched animals. The effect is probably one of slowing down of alveolar multiplication because the normal 8-wkold rats had significantly increased total number of alveoli compared to the approximately 7 -wk-old rats used as weight-matched controls for the tracheal banded animals. It is not clear why alveolar multiplication should be affected to this degree. One hypothesis considers elastic tissue to play a central role in alveolar acquisition (7). At birth, no alveoli are present in rats, and the terminal air spaces are simple tubular structures called primary saccules that are then subdivided by ridges, termed secondary crests, to form alveoli. An elastic fibre, together with collagen, attached to the alveolar epithelial basement membrane lies along the margin of the secondary crests, and a similar arrangement is present around the mouths of alveoli (2). The collagen-elastin network has a fishnet appearance, and it is thought that this network forms a semirigid tether through which lung tissue protrudes to form alveoli. If this hypothesis is correct, then diminution or alteration of the collagen-elastin network should diminish alveolar acquisition. We have recently shown (16) that administration of $\beta$-amino-proprionitrile which prevents the cross-linking of collagen and elastin markedly diminishes the total number of alveoli in the lung when the experiment is performed during the first $4 \mathrm{wk}$ of life in the rat. This change is also accompanied by abnormally large lungs with loss of elastic recoil. In the present experiment, however, there has been no apparent loss of elastin and collagen, rather an apparent increase in elastic tissue. The morphologic analysis of the data must be interpreted with caution. The data are of marginal statistical significance. Although the Humberston stain has slight tinctorial differences between collagen and elastin, the method of assessment electronically using a black and white image could not separate them. Further, the measurement is a relative one, i.e. number of pixel points to the total number. The tracheal banded animals tended to have less air per gram of lung tissue (Table 1) so that the absolute amounts of collagen and elastin may have been little different. Perhaps increased airway resistance has resulted in an abnormal synthesis and distribution of the collagen-elastin system so that the usual fishnet configuration with the meshes surrounding the mouths of alveoli is disturbed. In this experiment, inspiratory and expiratory resistance would be equal as opposed to the constant increase in transpulmonary pressure that occurs in the tracheal ligation experiment in fetal sheep in which lung enlargement occurs (1). It is difficult to image the control mechanism which induces interstitial cells to secrete an abnormal quantity or configuration of elastic tissue and collagen. Presumably, the primary stimulus must be interstitial distortion and stretching, but the signal from stimulus to secretion is probably a chemical one. Whatever the reason, tracheal banding provides a good model of a damaged lung to test the hypothesis that such a lung would not develop normally after subsequent removal of the ligatures or would be abnormally susceptible to damage by irritants such as tobacco smoke. It would also be very interesting to investigate collagen and elastin biochemistry in this model.

The alteration in mechanical properties of the lung are of interest. The loss of recoil pressure at high lung volumes in tracheal banded rats with air-filled but not saline-filled pressurevolume curves suggests that these alterations are due to decreased surface forces. A similar change in air-filled but not saline-filled pressure-volume curves after tracheal obstruction was noted by Buhain $e t$ al. (4). They placed valves in the trachea of adult dogs and noted that a subsequent loss of recoil at high lung volumes was only partially reversed 2 to 4 wk after removal of the valves. They likewise postulated that the changes were due to alterations in surface elastic forces. Gold et al. (10) measured elastic recoil in patients with asthma before and after treatment. They found that loss of recoil before treatment was reversible and thought the changes were due to alterations in surface properties. A decrease in surface force could be attributed to an increased stability of the surface film at high lung volumes which suggests that the mechanical effects of banding might have altered the rate of synthesis, secretion, or degradation of surface active material. Changes in breathing patterns have been shown previously to affect these factors $(8,17,20,22)$. A second explanation for this finding is that the diminished elastic recoil at high lung volumes is related strictly to the diminished surface to volume ratio found in these lungs; thus, the decreased recoil is not related to altered quality of surface forces, but simply to the diminished surface area. Why this should selectively affect elastic recoil at high and medium lung volumes and not at low volumes is unclear, but suggests that the altered collagen-elastin fibre arrangement resulting from the treatment produces subtle alterations in the stress response of the lung. We did not measure surface activity and made an unsuccessful attempt to quantitate lamellar bodies within type II cells and to quantitate type II cells, but had inadequate material for assessment. The tracheal banded models seem suitable for biochemical and physiochemical studies of surface phenomena of the lung.

The sham-operated animals almost invaribly had values between the experimental group and the nonoperated 8-wk-old animals for somatic. lung growth, and pressure-volume characteristics although no significant differences were noted between the sham-operated animals and the nonoperated ones. Similar findings occurred in a previous experiment in which the control animals received intraperitoneal injections of saline and were compared to animals injected with $\beta$-amino proprionitrile (16). These observations suggest that minor insults may have effects on lung growth and structure.

\section{REFERENCES AND NOTES}

1. Alcorn. D.. Adamson, T. M., Lambert. T. F., Maloney, T. E., Ritche, B. C., and Robinson. P. M.: Morphological effects of chronic tracheal ligation and drainage in the fetal lamb lung. J. Anat.. 123:649 (1977). 
2. Amy, R. W. M. Bowes, D., Burri, P. H., Haines, J. and Thurlbeck, W. M.: Postnatal growth of the mouse lung. J. Anat.. 124: 131 (1977)

3. Bonikos, D. S., Bensch, K. G., Norway, W. H., Jr., and Edwards, D. K.: Bronchopulmonary dysplasia: the pulmonary pathologic sequel of necrotizing bronchiolitis and pulmonary fibrosis. Human Pathol., 7: 643 (1976)

4. Buhain. W. J.. Brody. J. S., and Fischer, A. B.: Effect of artificial airways obstruction on elastic properties of lung. J. Appl. Physiol.. 33: 589 (1972).

5. Burri, P. H., Dbaly. J., and Weibel. E. R.: The postnatal growth of the rat lung I. Morphometry. Anat. Rec., 178: 711 (1974).

6. Colebatch, H. J. H., Ng. C. K. Y.. and Nikov, N.: Use of an exponential function for elastic recoil. J. Appl. Physiol., 46: 387 (1979).

7. Emery, J. L.: The post-natal development of the human lung and its implications for lung pathology. Respiration. 27 (Suppl.): 41 (1970).

8. Faridy, E. E.: Effect of distension on release of surfactant in excised dogs' lungs. Respir. Physiol.. 27: 99 (1976).

9. Gibson, G. J., Pride, N. B., Davis, J., and Schroter, R. C.: Exponential description of the static pressure-volume curve of normal and diseased lungs. Am. Rev. Respir. Dis., 120: 799 (1979).

10. Gold, W. M.. Kaufman. H. S., and Nadel. J. A.: Elastic recoil of the lungs in chronic asthmatic patients before and after therapy. J. Appl. Physiol.. 23: 433 (1967).

11. Gurwitz. D., Katten. M., Levison, H., and Culham. J. A. G.: Pulmonary function abnormalities in asymptomatic children following hydrocarbon pneumonitis. Pediatr. Res. (Abstract), 12: 561 (1978).

12. Holmes, C., and Thurlbeck, W. M.: Normal lung growth and response after pneumonectomy in rats at various ages. Am. Rev. Respir. Dis., 120: 1125 (1979).

13. Humberstone, G. C. W., and Humberstone. F. D.: An elastic tissue stain. J. Med. Lab. Technol., 26: $99(1969)$.

14. Katten, M., Keens, T. G.. Lapierre, J. G.. Levinson. H., Bryan, A. C.. and Reilly, B. J.: Pulmonary function abnormalities in symptom-free children after bronchiolitis. Pediatrics, 59: 683 (1977).

15. Keens. T. G., Chen. V., Patel, P.. O'Brien, P., Levison, H., and Ianuzzo, C. D. Cellular adaptations of the ventilatory muscles to a chronic increased respiratory load. J. Appl. Physiol., 44: 905 (1978).

16. Kida, K., and Thurlbeck. W. M.: The effects of $\beta$-aminopropionitrile in growing rat lung. M. J. Pathol., 101: 693 (1980).

17. Klass. D. J.: Dibutysyl cyclic GMP and hyperventilation promote rat lung phospholipid release. J. Appl. Physiol., 47: 285 (1979)

18. Mead, J., Whittenberger, J. L. and Radford. F. P., Jr.: Surface tension as a factor in pulmonary volume-pressure hysteresis. J. Appl. Physiol., /0: 191 (1957).

19. Novikoff. A. B. Shin. W.. and Drucker. J.: Mitochondrial localization of oxidation enzymes: staining results with two tetrazolium salts. J. Biophys. Bicchem. (ytol., 9: 47 (1961).

20. Oyarzum. M. J., and Clements, J. A.: Control of lung surfactant by ventilation. adrenergic mediators, and prostaglandins in the rabbit. Am. Rev. Respir. Dis. 117: 879 (1978).

21. Snyder, R. D., Collipp. P. J., and Greane. J. S.: Growth and ultimate height of children with asthma. Clin. Pediatr.. 6: 389 (1967)

22. Thet. L. A., Clerch. L., Massaro, G. D., and Massaro. D.: Changes in sedimentation of surfactant in ventilated excised rat lungs. Physical alterations in surfactant associated with the development and reversal of atelectasis. J. Clin. Invest.. 04: 600 (1979).

23. Thurlbeck, W. M.: Structure of the lung. In: John G. Widdicombe. Ed., Arthur C. Guyton. Series Ed.: Respiratory Physiology. pp. 1-36 (University Park Press, Baltimore. MD, 1977).

24. Thurlbeck, W. M., Kida, K., Langston, C., Cowan. M. J., Kitterman, J. A. Tooley, W.. and Bryan, H.: Postnatal lung growth after repair of diaphragmatic hernia. Thorax, 34: 338 (1979).

25. Dr. Kida is a Fellow of the Manitoba Lung Association (1978-1980)

26. The present address of Dr. Kozui Kida is: Department of Respiratory Disease Tokyo Metropolitan Geriatric Hospital. 35-2 Sakae-cho. Itabashi-ku. Tokyo. Japan. 173.

27. The authors thank Joan Mathers for carrying out the preparation of electron microscopic studies.

28. Requests for reprints should be addressed to: Dr. William M. Thurlbeck. Department of Pathology. Faculty of Medicine. University of British Columbia. 2211 Wesbrook Mall. Vancouver, British Columbia V6T IW5. Canada.

29. This research was supported by MRC Grant MA7124.

30. Received for publication February 27, 1980.

31. Accepted for publication June 13, 1980 . 